Results 458 patients receiving IMV (92\% via tracheostomy) were transferred (mean age 61 years, 259 (57\%) male, 421 (92\%) from external ICUs with a median ICU stay of 33 days. On arrival, 422 (92\%) were ventilator-dependent and 37 (8\%) required nocturnal IMV. The median $\mathrm{PaCO}_{2}$ was $10 \mathrm{kPa}$. Neuromuscular problems included Motor Neurone Disease (21\%), Tetraplegia (12\%), Muscular Dystrophies (11\%), and Myotonic Dystrophy (9\%).

417 (91\%) patients survived to hospital discharge, with 330 (72\%) weaned from IMV (median stay 24 days if decannulated, 37 days if IMV continued). Non-invasive ventilation (NIV) facilitated weaning in 79\%. From the date of ICU admission, $63 \%$ of the whole cohort were alive at 1 year, $43 \%$ at 3 years, and $33 \%$ at 5 years. When adjusted for case-mix, survival was similar for external and in-house referrals. At least 343 (82\%) survivors were discharged home. Further outcome data are summarised in Table 1.

COPD patients had the lowest rate of death and/or failed decannulation (13\%); further, long-term NIV was associated with a significant increase in survival $(\mathrm{p}=0.01)$, despite normocapnia $(5.9 \mathrm{kPa})$ if completely weaned. $33 \%$ neuromuscular patients required long-term IMV, typically due to bulbar problems, although $65 \%$ were discharged home. Continued IMV in other groups conferred a very poor prognosis.

Conclusions These data confirm high levels of survival and discharge home in patients referred to a specialised weaning service. Repatriation to the referring ICU was rarely necessary. NIV was important in the graded withdrawal of IMV and the provision of domiciliary care. In COPD, NIV use on discharge was associated with improved survival. Overall outcomes were favourable when compared to international data and are supportive of current national service plans.

\begin{tabular}{|c|c|c|c|c|c|c|c|}
\hline \multirow[t]{2}{*}{ Total (N) } & \multirow{2}{*}{$\begin{array}{l}\begin{array}{l}\text { Hospital } \\
\text { survival }\end{array} \\
\mathrm{N}(\%) \\
\end{array}$} & \multicolumn{2}{|c|}{ Ventilator-free } & \multicolumn{2}{|c|}{ Domidiary NIV } & \multicolumn{2}{|c|}{$\begin{array}{c}\text { Continued invasive } \\
\text { ventilation }\end{array}$} \\
\hline & & $N(\%)$ & Survival & $N(\%)$ & Survival & $N(\%)$ & Survival \\
\hline Neurom uscular (165) & $199(96)$ & 36 (22) & $37(6-110)$ & $68(41)$ & $34(12-78)$ & $55(33)$ & $17(2.34)$ \\
\hline $\operatorname{COPD}(104)$ & $97(93)$ & $49(47)$ & $17(5-27)+$ & $43(41)$ & $27(5-62)^{+}$ & $5(5)$ & $4(1-13)$ \\
\hline Post-surgica (66) & $58(88)$ & $27(41)$ & $47(6-92)$ & $17(26)$ & $17(2-55)$ & $13(20)$ & $1(0-58)$ \\
\hline Other Respiratory (50) & $37(74)$ & $19(38)$ & $12(2-100)$ & $14(28)$ & $31(5-90)$ & $4(8)$ & $2(1-24)$ \\
\hline Chest wall (35) & $34(97)$ & 3(9) & $156(13)$. & $28(80)$ & $76(30.165)$ & $3(9)$ & 5(3.) \\
\hline Other (38) & $32(84)$ & $8(21)$ & $57(4155)$ & $18(47)$ & $75(27.142)$ & $6(16)$ & $2(0.8)$ \\
\hline All (458) & $417(91)$ & $142(31)$ & $20(5-78)$ & $188(41)$ & $37(12-81)$ & $86(19)$ & $6(1-31)$ \\
\hline
\end{tabular}

\section{S136 AN OBSERVATIONAL COHORT STUDY TO DETERMINE THE SAFETY, EFFICACY AND OUTCOME OF THE EARLY INITIATION OF PRESSURE SUPPORT VENTILATION DURING MECHANICAL VENTILATION}

${ }^{1} G$ Glover, ${ }^{2} B$ Connolly, ${ }^{1} S$ Di Gangi, 'L Ayers, 'M Terblanche, ${ }^{1} R$ Beale, ${ }^{3} \mathrm{~N}$ Hart; ${ }^{1}$ King's Health Partners, Department of Critical Care, Guy's and St Thomas' NHS Foundation Trust, London, UK; ${ }^{2}$ Division of Asthma, Allergy and Lung Biology, King's College London, London, UK; ${ }^{3}$ King's Health Partners, Lane Fox Respiratory Unit, Guy's \& St Thomas' NHS Foundation Trust, London, London, UK

\subsection{6/thoraxjn-2013-204457.143}

Introduction Identifying the earliest time for initiation of weaning from mechanical ventilation (MV) is important. Weaning trials and guidelines apply screening criteria which have not been validated and which may actually delay weaning from MV if too

\begin{tabular}{|c|c|}
\hline $\begin{array}{l}\text { Abstract S136 Table } \\
\text { support at initiation of }\end{array}$ & and organ \\
\hline Neurological & \\
\hline RASS & $-2(-2--3)$ \\
\hline RASS $=-5(\%)$ & $2(1)$ \\
\hline RASS $=-4(\%)$ & $18(9)$ \\
\hline RASS $=-3(\%)$ & 70 (34) \\
\hline Sedation in 24hrs prior to PSV & $730(240-1690)$ \\
\hline Propofol, mg & $400(0-1175)$ \\
\hline Fentanyl, mcg & \\
\hline Respiratory & \\
\hline $\mathrm{PaO}_{2}: \mathrm{FiO}_{2}$ ratio $(\mathrm{kPa})$ & $35.8 \pm 15.9$ \\
\hline PEEP $\left(\mathrm{cmH}_{2} \mathrm{O}\right)$ & $7.5 \pm 2.5$ \\
\hline $\mathrm{pH}$ & $7.35 \pm 0.07$ \\
\hline $\mathrm{PaCO}_{2}(\mathrm{kPa})$ & $5.7 \pm 1.3$ \\
\hline Cardiovascular & \\
\hline Heart rate (bpm) & $88 \pm 17$ \\
\hline Mean arterial pressure $(\mathrm{mmHg})$ & $77 \pm 11$ \\
\hline Requiring vasoactive drugs (\%) & $88(42)$ \\
\hline SOFA & \\
\hline SOFA (total) & $6(4-8)$ \\
\hline Respiratory & $1(1-3)$ \\
\hline Cardiovascular & $1(1-3)$ \\
\hline Renal & $0(0-2)$ \\
\hline Hepatic & $1(0-1)$ \\
\hline Haematological & $0(0-2)$ \\
\hline Glasgow Coma Sale ${ }^{b}$ & $0(0-0)$ \\
\hline $\begin{array}{l}\text { Data are presented as percentage } \\
\text { range). } \mathrm{n}=209, \text { except }{ }^{\mathrm{a}} \mathrm{n}=1 \\
\text { Abbreviations: } R A S S=\text { Richmono } \\
\text { ventilation. PaO } \mathrm{O}_{2}=\text { arterial parti } \\
\text { PEEP }=\text { positive end expiratory } \\
\text { ide. SOFA }=\text { sequential organ fal }\end{array}$ & $\begin{array}{l}\text { dian (Interquartile } \\
\text { dation. } \\
\text { pressure support } \\
\text { f inspired oxygen. } \\
\text { e of carbon diox- }\end{array}$ \\
\hline
\end{tabular}

prescriptive. This study aimed to observe physician-led utilisation of pressure support ventilation (PSV), referenced to four screening criteria commonly reported in weaning trials $\left(\mathrm{PaO}_{2}: \mathrm{FiO}_{2}\right.$ $\geq 26.3 \mathrm{kPa}$, positive end expiratory pressure (PEEP) $\leq 5 \mathrm{cmH}_{2} \mathrm{O}$, Richmond Agitation and Sedation Scale (RASS) $>-3$ and cardiovascular stability (HR $<120$, MAP $>65 \mathrm{mmHg}$ and no inopressor support)), hypothesising that these criteria would not predict ability to sustain a PSV trial for 24hours.

Method Prospective observational cohort study of adult patients receiving MV in a thirty-bed ICU in a university hospital. Routine post-operative patients were excluded. Logistic regression analysis identified factors associated with PSV failure. Outcome is reported according to adherence to the screening criteria.

Results 209 patients were included (mean \pm SD age $62.6 \pm$ 15.9years, M:F 115:94, APACHE II $16.7 \pm 6.1,48 \%$ medical, 20\% elective surgical, 32\% emergency surgical admissions). Median (IQR) time to initiate PSV was 11.0 (5.0-22.0) hours, and duration of weaning to extubation was 43.0 (13.0121.5)hours. PSV weaning was initiated despite significant hypoxia $\left(\mathrm{PaO}_{2}: \mathrm{FiO}_{2} 35.8 \pm 15.9 \mathrm{kPa}\right)$, moderate PEEP levels $\left(7.5 \pm 2.5 \mathrm{cmH}_{2} \mathrm{O}\right)$, deep sedation $(44 \%$ RASS $\leq-3)$ and cardiovascular instability $(48.8 \%$ ) (Table 1 ). At PSV initiation, $85 \%$ of patients violated at least one screening criterion, yet $74.6 \%$ of patients remained stable for 24 hours. Logistic regression identified no association between individual screening criteria and PSV failure. Failure to sustain a PSV trial was associated with ventilation $>7$ days $(\mathrm{RR}=2.12[1.33,3.38] \mathrm{p}=0.002)$ and ICU mortality $(\mathrm{RR}=2.94[1.46,5.94] \mathrm{p}=0.002)$.

Conclusion Physician-led PSV weaning was often initiated early before patients fulfilled conventional screening criteria. Despite 
this, PSV trials were well tolerated in the majority with active weaning in pressure support subsequently achieved. Individual screening criteria were not associated with PSV failure. Of clinical significance, failure to sustain a PSV trial could be an early indicator of prolonged mechanical ventilation and ICU mortality, and predictive characteristics of this warrant further investigation. Application of screening criteria, as reported in weaning literature, may delay initiation of weaning in some patients.

\section{S137 FAILURE OF NICE GUIDANCE CG83 IMPLEMENTATION: NATIONAL UK SURVEY OF REHABILITATION SERVICES FOR SURVIVORS OF CRITICAL ILLNESS}

${ }^{1} \mathrm{~B}$ Connolly, ${ }^{2} \mathrm{~L}$ Denehy, ${ }^{1} \mathrm{~J}$ Moxham, ${ }^{3} \mathrm{~N}$ Hart; ${ }^{1}$ Department of Asthma, Allergy \& Respiratory Science, Division of Asthma, Allergy and Lung Biology, King's College London, London, UK; ' ${ }^{2}$ Department of Physiotherapy, School of Health Sciences, University of Melbourne, Melbourne, Australia; ${ }^{3}$ Lane Fox Clinical Respiratory Physiology Research Unit, St. Thomas' Hospital, Guy's \& St. Thomas' NHS Foundation Trust, London, UK

\subsection{6/thoraxjnl-2013-204457.144}

Introduction National guidelines advocating multidisciplinary rehabilitation delivered throughout the continuum of recovery following critical illness were published in 2009 (NICE CG83). However, lack of supporting evidence for these recommendations has resulted in inconsistent implementation, particularly in the post hospital discharge phase. As expected, nursing and medical staff have been surveyed for involvement in intensive care unit (ICU) follow-up with previous surveys of physiotherapy practice focussed on within-ICU rehabilitation practice. This survey aimed to characterise post critical illness follow-up and rehabilitation following hospital discharge.

Method A predominantly closed-question, physiotherapy-specific postal survey distributed to senior critical care clinicians at UK hospitals with a listed ICU, excluding specialist-only units, and coded to facilitate respondent identification.

Abstract S137 Table 1. Barriers to availability of post hospital discharge rehabilitation programmes for post critical illness patients.

\begin{tabular}{lll}
\hline Barrier & $\begin{array}{l}\text { Frequency } \\
\text { reported } \\
\text { overall } \mathbf{n}(\%)\end{array}$ & $\begin{array}{l}\text { Frequency reported } \\
\text { as main barrier }\end{array}$ \\
\hline Lack of funding & $147(90.7)$ & $98(63.6)$ \\
Lack of sufficient staff & $127(78.4)$ & $17(11.0)$ \\
Resources prioritised to other & $70(43.2)$ & $4(2.6)$ \\
patient groups/clinical areas & & \\
Not considered required service & $66(40.7)$ & $22(14.3)$ \\
at managerial level & & \\
Lack of available space & $50(30.9)$ & $2(1.3)$ \\
Insufficient patient numbers to justify & $34(21.0)$ & $10(6.5)$ \\
Extra-contractual (out-of-area) patient caseload & $15(9.3)$ & $0(0.0)$ \\
Lack of trained staff & $12(7.4)$ & $0(0.0)$ \\
No evidence & $4(2.5)$ & $0(0.0)$ \\
Not sure what to include in a programme & $2(1.2)$ & $0(0.0)$ \\
Other (time constraints) & $1(0.6)$ & $1(0.6)$ \\
\hline For frequency of reported barriers overall, $\mathrm{n}=162$ responses. & For frequency of reporting \\
as main barrier, $\mathrm{n}=154$ responses. & & \\
&
\end{tabular}

Results Physiotherapists at 240 identified ICUs were sent surveys. 182 surveys were returned $(75.8 \%$ response rate), including one blank survey. $36.5 \%$ were from university teaching hospitals, $63.5 \%$ from district general hospitals. Forty-eight centres reported follow-up services at 2-3months, the majority as clinics $(39 / 48,81.3 \%)$. Physiotherapists were involved in 43 follow-up services, albeit in a third of cases, on a referral-only basis. Critical care nursing staff were the main other clinician involved. Health-related quality of life $(83.3 \%)$ and psychological status $(81.3 \%)$ were the main items addressed, with exercise capacity reviewed in almost $60 \%$ of cases. Only $12 / 182(6.6 \%)$ centres reported post hospital discharge rehabilitation programmes, all including an exercise component, but only four offering education topics. Substantial variation existed between programmes regarding eligibility, delivery format, structure, content and evaluation. Where rehabilitation programmes were not available, barriers to offering this service were detailed (Table 1). Lack of funding was the most frequently reported, and the main barrier listed. The majority of respondents (96/169; 56.8\%) reported referral of post critical illness patients into alternative rehabilitation streams, predominantly accessing community and domiciliary in-patient or out-patient services.

Conclusion Data from this survey demonstrated a low level of available follow-up and rehabilitation services for post critical illness patients following hospital discharge. This reflects a lack of implementation of high-profile national guidelines, the main reason for which was reported to be lack of funding. Further investment in these services is required.

\section{Mechanisms in pulmonary vascular disease}

\section{S138 BLOOD OUTGROWTH ENDOTHELIAL CELLS ISOLATED FROM PATIENTS WITH PULMONARY ARTERIAL HYPERTENSION POSSESS LESS CAVEOLAE AND REDUCED CAVIN-2 EXPRESSION}

${ }^{1} \mathrm{BJ}$ Dunmore, ${ }^{2} \mathrm{G}$ Howard, ${ }^{1} \mathrm{~A}$ Crosby, ${ }^{2} \mathrm{BJ}$ Nichols, ${ }^{1} \mathrm{NW}$ Morrell; ${ }^{1}$ University of Cambridge, Cambridge, United Kingdom; ${ }^{2}$ MRC Laboratory of Molecular Biology, Cambridge, United Kingdom

\subsection{6/thoraxjnl-2013-204457.145}

Pulmonary arterial hypertension $(\mathrm{PAH})$ is a progressive disease characterised by a marked elevation in pulmonary arterial pressure due to increased muscularisation and obliteration of small pulmonary arteries. The majority of heritable PAH cases are due to mutations in members of the transforming growth factor- $\beta$ (TGF $\beta$ ) receptor signalling pathway. Although predominantly associated with mutations in the bone morphogenetic protein type II receptor (BMPR-II) genetic variations causing disease have recently been identified in caveolin-1, the major component of caveolae generation. Caveolae are flask shaped invaginations in the plasma membrane that play an important role in many endothelial cell functions including vesicular trafficking and signalling. Correct caveolae formation in the lung has recently been shown to require serum deprivation protein response (SDPR), also known as cavin-2. Using blood outgrowth endothelial cells (BOECs) isolated from patients with $\mathrm{PAH}$ we sought to determine the expression of cavin-2 and caveolae formation.

Methods Blood outgrowth endothelial cells (BOECs) were isolated from control subjects and individuals with $\mathrm{PAH}$, including BMPR-II mutation and idiopathic patients. Following transmission electron microscopy (TEM) the number of caveolae and depth of invaginations were assessed in ten cells from each cell line. Protein expression of caveolin-1, cavin-1 and cavin-2 were assessed by western blotting. Caveolin-1 and cavin-2 knockout 